VASCULARISATION OF THE WHOLE VITREOUS IN A CASE OF HAEMORRHAGIC RETINITIS, WITH RETENTION OF NORMAL ACUITY OF VISION

BY

D. V. GIRI

EASTBOURNE

MR's. E.P., aged 62 years, a patient of the Royal Eye Hospital, Eastbourne, was first seen by me in 1919, when the eyes were healthy. Seen by Mr. G. B. Lowe, in June, 1925, he noted "very hazy media, each eye, but nil seen to account for same." Again in June, 1929, she came complaining of temporal headaches, seeing black spots, and a sort of cloud in front of L.E. especially when reading; then the R.E. was healthy; in the L.E. there was no appreciable change in the media, but there were numerous flameshaped retinal haemorrhages in the central region; nothing abnormal was noted about the retinal vessels. She was referred to her Doctor, and his report ran "...I have attended her for sundry ailments from time to time, chiefly 'colds,' etc. Heart sometimes irregular, accentuated 2nd sound, B.P. 150. Urine-trace of albumen-no deposit - not examined microscopically. Patient has a cystic goitre."

The patient was put under treatment, and kept under periodical observation. March 20, 1930.-R.E. Media and fundus normal. L.E. Haemorrhages considerably absorbed. A number of pale yellow angioid streaks seen.

June 30, 1930.-R.E. Media and fundus normal. L.E. The whole disc is veiled by a thin membrane; the angioid streaks persist ; haemorrhages further absorbed.

September 22, 1930.-A gossamer-like vascularised membrane masking disc and extending across vitreous in all directions. Best seen with the Gullstrand ophthalmoscope binocularly.

February 9, 1931.-What was noted as angioid streaks appears to be an obliterated artery. The sheaf of arborescent vessels in membrane exceedingly well marked. The retinal arteries are very fine and some have become spiral.

November 19,1931. - At the disc, the superior temporal retinal vein is extremely attenuated or obliterated. The sheaf of vessels is growing further forward into the vitreous. Fresh retinal haemorrhages.

May 30, 1932.-Gullstrand binocular ophthalmoscopy : L.E. the arborescent vascularisation involves the whole vitreous, and the vessels seem to reach up to the anterior end of the vitreous. 
November 31, 1932. - The vascularisation of the vitreous persists; the branching appears dichotomous, but there are no free terminals, all ending in loops and constituting an unbroken network. No haemorrhage seen.

R.V. $\bar{c}+1 \cdot 0$ D. sph. $0+1.75$ D. cyl. axis horiz. $6 / 6$ partly.

L.V. $\bar{c}+1 \cdot 0$ D. sph. $0+1 \cdot 5$ D. cyl. axis horiz. 6/12 partly.

On February 14, 1933.-

c gls. R.V. 6/6 partly, L.V. 6/6 partly.

The fundi were again examined, both in the usual way, and binocularly with the Gullstrand ophthalmoscope. R.E. Media clear, fundus normal, but for a spot of haemorrhage down and out about 2 D.D.s from disc. L.E. vitreous clearer than ever. The vessels in the vitreous persist, but give the impression of having become finer. Probably they are undergoing involution.

It is noteworthy that in spite of the extraordinary pathological condition and considerable loss of nasal field for 10/330 white, as shown in the chart, the L.E. preserves such good vision. This is the first case of complete vascularisation I have seen, and I am not aware of any such case on record.

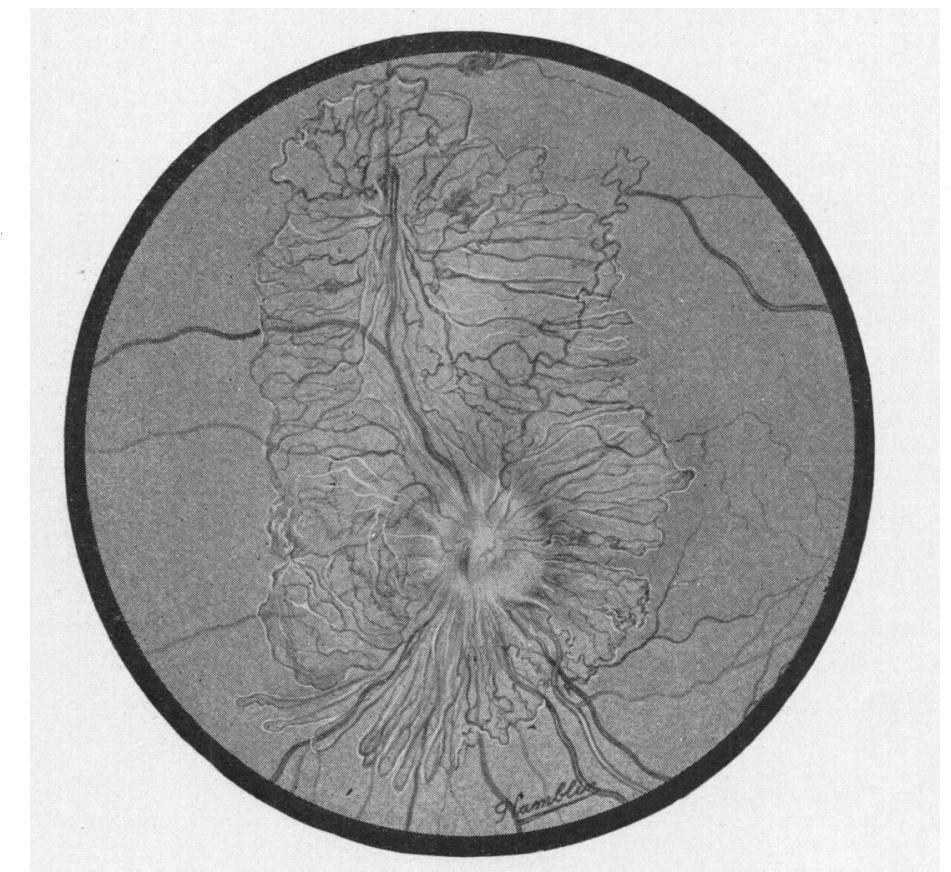

N.B.-In actual ophthalmoscopic examination no part of the fundus can be seen clear of the vessels that fill the vitreous, as is shown in the drawing. What looks flat in the drawing has to be visualised as an arborescence extending axially forwards towards the back of the lens. 


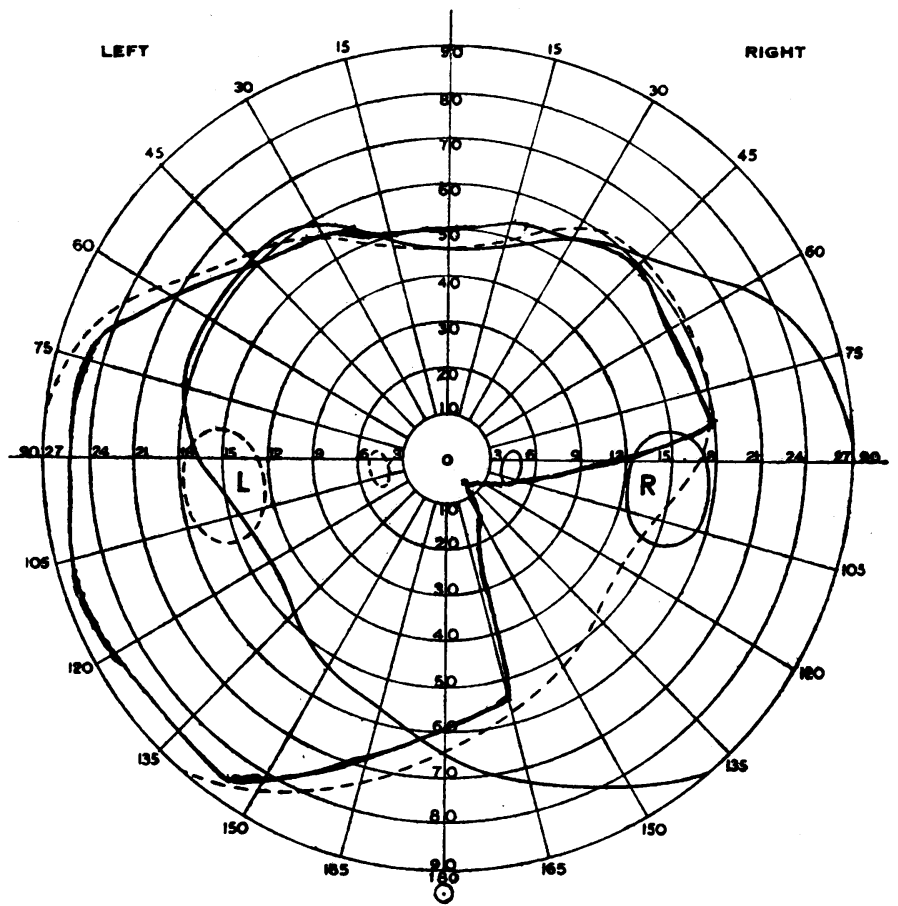

From June, 1929, to July, 1930, the treatment consisted in subcutaneous injections of 1 c.c. of "Collosol" Iodine, every other day, and taking internally:-

Plasmona, a dessertspoonful t.i.d. at meals, "Tabloid" Mixed

Glands (female) B. W. \& Co., 1 tablet, and parathyroid gland 1/40

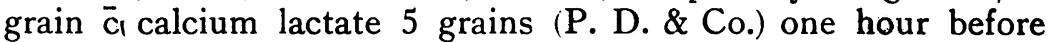
food, with intermissions of two to four weeks about every three months.

From July, 1930, until August, 1931, the subcutaneous injections of iodine and the parathyroid and calcium lactate tablets were dropped, and Riodine (a pill containing an organic compound of iodine) 1 t.i.d. and Calcium Diuretin (Knoll) 1 t.i.d. half-an-hour after food, by the mouth, were prescribed instead, with occasional breaks of a fortnight to a month.

This almost complete absence of fibrosis and prevention of retinitis proliferans, the striking clarity of the vitreous and remarkable acuity of vision are in great measure ascribable to the line of treatment adopted and the long period it was persisted in.

This case was shown at the clinical meeting of the ophthalmic section of the Royal Society of Medicine, held on January 13, 1933.

P.S.-Patient gets attacks of bad frontal pain followed by unconsciousness, for how long she does not know. The attacks come on 
about once in six months, and last about an hour. At the end of attack, patient feels exhausted and goes to sleep. Said to be still during the attacks. Has had five attacks in two years. Has been exceedingly well since the beginning of last summer.

N.B.-Since writing this report I have seen the patient several times. L.V. was $6 / 9$ on August 8,1933 . She started internal medication and as she began to get better she took ill, and had to stop it. On October 9, 1933, L.V. was 6/12. On October 25, she noted that the L.E. went suddenly worse. On November 2, a detachment of the retina at the lower periphery was evident in the L.E. On November 9, it was seen to be more extensive.

Owing to the pathological condition of the L.E., and the useful $R$. eye, as well as her very unsatisfactory general condition, it has not been considered advisable to operate for the detachment.

\section{NEW VESSEL FORMATION IN THE VITREOUS}

BY

GORDON FLINT, M.D., F.R.C.S.ED.

AN D

DAVID HARRINGTON, M.D.

FIRST UNIVERSITY EYE CLINIC, VIENNA

(DIRECTOR : PROFESSOR DR. MELLER)

LEBER $^{1}$ has described new vessel formation in the vitreous, the vessels arising from the retina as well as from the disc. The formation of new vessels, usually small capillaries, frequently follows inflammatory processes of the retina and particularly of the disc, but these are so minute that they can hardly be observed as such, and merely give the appearance of a somewhat hyperaemic disc. When their calibre is larger they appear on the disc as fine radial vessels.

New vessels which are visible ophthalmoscopically arise most frequently from deep and chronic inflammatory processes, resulting in localized disturbance or interruption of the circulation. Into the exudates which are formed, the new vessels grow.

They have also been observed in cardiovascular disturbances, particularly when associated with vascular disease of the retinal vessels.

In such cases there is often developed a system of collateral vessels, which take over the nutrition of the retina. This type of new vessel formation is not infrequently seen in arterio-sclerosis which has ended in an obliteration of the arteries.

Less often it is seen after thrombosis of the central vein or.its 